\title{
An imperfect Irish shrine recently purchased by the Royal Irish Academy
}

By E. C. R. Armstrong, F.S.A., Local Secretary for Ireland

The Royal Irish Academy recently purchased from Mr. $\mathrm{H}$. Naylor, a Dublin dealer, a portion of an Irish shrine together with two fragments supposed to have belonged to it. These had been obtained at the sale held at Killua, co. Westmeath, early in June 1920, having formed part of a large number of Irish antiquities collected by Sir Benjamin Chapman, fourth baronet.

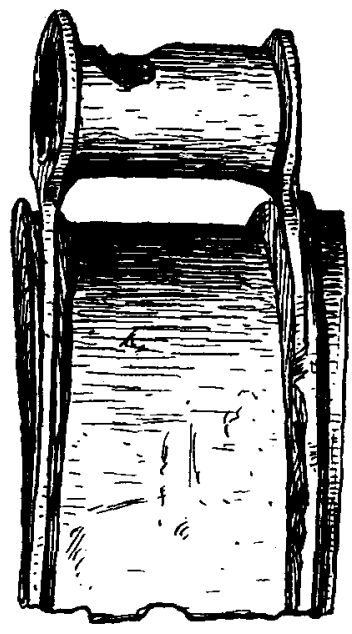

FIG I. Side of Shrine to show handle. $\left(\frac{1}{1}\right)$

No catalogue recording the localities or origin of the specimens appears to exist, and $\mathrm{Mr}$. E. Crofton Rotheram, of Belview, Crossakeel, co. Meath, who helped Sir Montagu Chapman to arrange the collection many years ago, has informed me that few of the specimens were localized.

The history of the shrine portion therefore is at present unknown. It is uninscribed, so its dating must rest upon stylistic grounds.

As will be seen from the illustrations it is semicircular in shape, measures $5.2 \mathrm{in}$. in length, $2 \cdot 3$ in. in height, and $x \cdot 2$ in. in breadth. At each side (plate V and fig. I) is a pierced tube 0.7 in. in diameter, suggestive of handles, which would appear to have been used for suspending the reliquary on certain occasions round the neck of its custodian. It may, however, be objected that the form of the tubes is hardly a practical one for handles, and their use as such is not insisted upon.

The shrine is made up of cast bronze plates, and is enriched with settings of amber. The front is gilt, and the design upon it is cut out of the bronze plate, but on the side to the observer's left can be seen the broken part of a gilded bronze plate, which appears, as there is a nail to fix it to the other side, to have been carried across and to have closed in the part at present open.

The principal feature of the decoration is a conventionalized male figure whose face is framed in a raised lozenge, the topmost point 

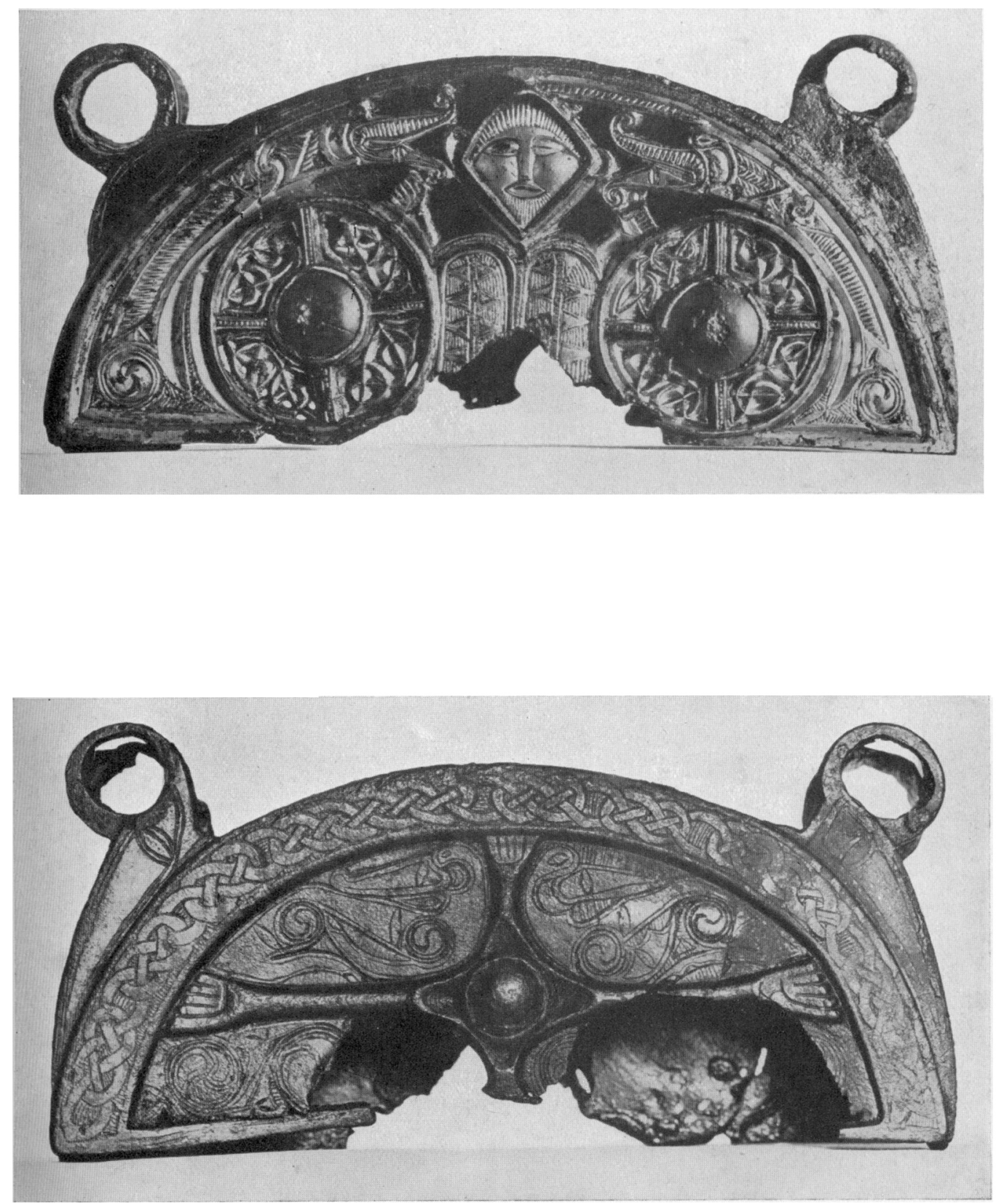

THE KILLUA SHRINE, FRONT AND BACK

(SLIGHTLY UNDER NATURAL SIZE) 
of which projects 0.2 inches over the face; the eyes are long, the mouth is placed directly below the nose; a beard and hair are shown; the ears are placed outside the lozenge. Possibly this framing was intended to indicate a hood with a pointed top ; but, if so, it is difficult to understand the ears being placed outside it. The arms are raised and the fingers clenched, apparently grasping the lower jaws of the confronting animals. The body is divided down the centre, and on each side it is ornamented with triangles placed base to base on either side of a beaded line, the background being shaded.

This figure does not resemble those to be seen on the shrine of St. Maodhóg, nor the later examples carved on the Irish high crosses. The figures on the shrine of St. Manchán are more akin to it, in that they have elongated eyes, but the faces of the St. Manchán figures are larger and narrower; the nose is differently formed and in no case is the mouth placed directly below it.

At each side of the human figure is placed a conventionalized animal with a head recalling that of a crocodile, whose long turned-back mouth is opened and appears to be biting the ear of the figure. The two crocodile-like animals resemble each other in form, but differ in certain details. Their eyes are placed above the ending of the upper jaw. In each case the fore limb is returned on the body. The hind limb is well marked; its upper portion begins with a spiral, while the lower part, showing two toes, is curved round the outside of the amber-centred disc. The bodies of the animals are ridged.

A human figure supported on each side by animals is an ancient and widely spread design. ${ }^{\mathrm{I}}$ A variant of this, in which animals gape with open jaws on each side of the figure, is not uncommon in Irish Christian art. In metal work it may be seen on the shrine of the Stowe Missal, where it occurs thrice, in one example being combined with a second pair of supporting animals. ${ }^{2}$ The same duplicated form, with the lower animals replaced by human figures, is found on the Carndonagh cross, co. Donegal. Salin ${ }^{4}$ has figured examples of Scandinavian metal-work showing animal forms gaping at each side of a man's head.

A disc $\mathrm{I} \cdot 3$ inches in diameter, with a central setting containing a half-bead of amber with an attachment through the centre, is placed on each side of the body of the figure. From the setting radiate four arms making a cross. On the panel to the

- See Evans, Journal of Hellenic Studies, xxi, pp. 163-9.

2 Warner, Henry Bradshaw Society, xxxii, plates III, Iv, v.

3 Crawford, Journal of Royal Society of Antiquaries of Ireland, xlv, p. 185.

${ }^{4}$ Die altgermanische Thierornamentik, figs. 394, 490 .

VOL. I 
observer's left the tops of all the arms are beaded; in that on the right the top one is plain.

The spaces between the arms are filled with raised interlaced work. It may be noticed that in the upper left panel of the disc, to the observer's right, the band is divided in two by a ridge.

It will be seen that the details of the supposed handles of the shrine differ; also that at the head of the figure to the observer's right is a ridged band which extends as far as the top of the animal's eye ; this is not repeated on the left.

The ornamentation of the back of the shrine, on which there is no trace of gilding, may now be described. Its circumference is decorated by a band of knot-work interlacing derived from a four-cord plait, placed over a hatched background. Below this is a raised cross having in the centre an amber half-bead inserted in a circular socket within a quatrefoil setting. The three complete limbs of the cross end in what are apparently meant for hands, though the circular form of the edge has caused the designer to make the thumb longer than the fingers. It is probable that the fourth limb also ended in a hand, for the line confining the design seems to have been carried across, and this would hardly have allowed space for any other form of termination.

In the two upper spaces between the arms of the cross are engraved two conventionalized animals similar in structure though differing in detail. Their general form and front and hind limbs can be easily detected. They may be compared with Salin's figure 565 a. The lower spaces were filled with a running design of whorls, the spandrils being ornamented with trefoils.

The two fragments obtained with the shrine, supposed to have formed part of it, consist of a damaged gilded bronze plaque (fig. 2) measuring $\mathrm{I} \cdot 6$ in. in length from the unbroken edges; when complete it was apparently square. It is ornamented with a cross placed saltirewise, having at the centre and at each of the arms sockets set with half-beads of amber, of which only two remain. The spaces between the beaded arms of the cross are decorated with spirals of the same form as those on the front of the shrine which mark the junction of the animal's limbs.

The other fragment (fig. 2) is merely a socket, showing traces of gilding, set with a half-bead of amber having an attachment through its centre. I am unable to suggest a reconstruction of the missing portion of the shrine to include these fragments.

The shape of the shrine portion would suggest that it was that part of a bell-shrine which enclosed the handle of the bell. Comparison both in shape and decoration with the handle of the Corp-Naomh bell-shrine, though of considerably later date, is 
inevitable. A consideration, however, might be urged against this if the two tubes are considered to have been handles. For had the lower part which enshrined the bell been in proportion, it would have been too heavy to have been suspended by the top. It may be remembered that the handles on the shrine of St. Patrick's bell are attached to the centre of the lower and heaviest part of the shrine.

Two bronze plates strongly riveted to the sides of the Killua shrine, and broken off where the portion ends, can be seen. These were evidently the attachments for the lower portion of the shrine.

The shape of the top of the shrine is so like the top of a bell-shrine that possibly it was made to enshrine a portion of a bell, the lower part of which was broken, thus requiring only a small case, whose weight would have allowed it to be lifted by the top, always supposing that the two tubes were handles.

The next point is the date to which the Killua shrine is to be assigned. Its ornamentation, omitting the human figure and the cross, falls into three classes-spiral, interlaced, and zoomorphic.

The spiral ornament is early in type, and on these grounds alone I
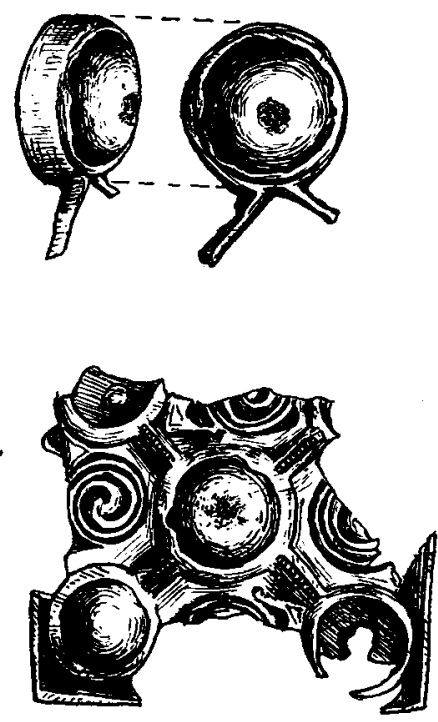

Fig. 2. Fragments supposed to have formed part of Shrine. $\left(\frac{1}{1}\right)$ should not consider the shrine to be later than the eighth century. The interlaced ornament is of a simple character not unlike that found in the Book of Durrow. The deciding point with regard to the zoomorphic ornament seems to be the occurrence of the spiral ; for, according to Salin, ${ }^{\text {I }}$ the two occur together first in the Book of Lindisfarne, which may be dated early in the eighth century. Zoomorphic combined with spiral ornament which can be dated early in the eighth century is also met with in North Europe, being a feature of Salin's 'Style III '.

It would therefore seem that the Killua shrine may be provisionally dated to the eighth century.

$$
\text { I Op. cit., p. } 357 \text {. }
$$

